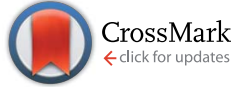

Cite this: RSC Adv., 2017, 7, 1387

Received 2nd November 2016 Accepted 15th December 2016

DOI: 10.1039/c6ra26161b

www.rsc.org/advances

\title{
Microwave roasting with size grading based on the influence of carbon on vanadium extraction from stone coal via microwave roasting-acid leaching
}

\author{
Yi-zhong Yuan, ${ }^{\star a b c}$ Yi-min Zhang, ${ }^{\star a b c}$ Tao Liu ${ }^{a b c}$ and Tie-jun Chen ${ }^{a b c}$
}

Carbon in stone coal has a double-edged function in the microwave roasting-acid leaching of stone coal; it provides stone coal with good heating characteristics, but it hinders the oxidization of vanadium and causes the sintering phenomenon. Adjustment of the particle size and microwave input power is performed to use the advantages of carbon and avoid its disadvantages. Fine particles are not suitable for direct microwave roasting due to their low heating rate, low final temperature and serious sintering phenomenon. However, for coarse particles, a high microwave input power causes more carbon to be retained in the stone coal in the heating stage to obtain a high heating rate and final temperature. These carbon particles are removed in the temperature holding stage because of the unique cracks and pores of coarse particles under the high microwave input power condition. Comprehensively considering the heating characteristics and vanadium leaching efficiency of stone coal, a 1-3 $\mathrm{mm}$ particle size and 1200-1800 W microwave input power are suitable for the microwave roasting of stone coal. The vanadium leaching efficiency of the roasted sample in this condition is $14 \%$ higher than the roasted sample without size grading

\section{Introduction}

Stone coal is an important vanadium resource, which is widely distributed in several provinces of China. Most of the vanadium in stone coal exists as V(III) (trivalent vanadium), which substitutes for $\mathrm{Al}^{3+}$ in the dioctahedron of mica group minerals as isomorphism. ${ }^{1-4}$ The traditional technology for vanadium extraction, which is the chloridizing roasting-water leaching technique, is gradually being replaced by blank roasting-acid/ alkaline leaching or direct acid leaching because of serious environmental pollution. ${ }^{5,6}$ For stone coal that has a high ratio of vanadium in its mica lattice, the roasting process has a significant effect on the acid leaching efficiency of vanadium. In the roasting process, the reducing materials are oxidized, the mineral structures are preliminarily destroyed, and the vanadium valency changes from the trivalent state to the pentavalent state gradually. ${ }^{7,8}$ All of these changes are simulative of vanadium leaching from stone coal.

The study and utilization of microwaves in the mineral and metallurgy field are becoming more and more intensive., ${ }^{\mathbf{9} 10}$

${ }^{a}$ College of Resource and Environmental Engineering, Wuhan University of Science and Technology, Wuhan 430081, China. E-mail: yyz2038@163.com; zym126135@126. com; Tel: +86-159-27698430; +86-027-68862057

${ }^{b}$ Hubei Provincial Engineering Technology Research Center of High Efficient Cleaning Utilization for Shale Vanadium Resource, Wuhan 430081, China

${ }^{c}$ Hubei Collaborative Innovation Center for High Efficient Utilization of Vanadium Resources, China
Microwaves could be utilized for the treatment of ores in some of the unit operations, such as drying, calcining, pretreatment, prereduction roasting and smelting. ${ }^{11}$ Microwaves are a form of electromagnetic radiation with frequencies in the range of 0.3-300 GHz. Due to its different heating mechanism from conventional methods, the heating characteristics of materials in microwaves are related to their properties. Materials with high complex permittivity $(\varepsilon)$ or complex permeability $(\mu)$ (for magnetic materials) generally have good microwave absorbing properties and heating characteristics in microwave fields. If the thermal radiation of materials and thermal effect of reactions are considered, the heating rate of materials in the microwave field can be expressed as eqn (1). ${ }^{12}$ With regard to natural ores consisting of various minerals, their heating characteristics depend on the microwave absorbing components, thermal radiation and thermal effect of reactions.

$$
\frac{\mathrm{d} T}{\mathrm{~d} t}=\frac{1}{\rho C p}\left(2 \pi \varepsilon_{0} \varepsilon f_{\mathrm{m}} E^{2}-\frac{e a A}{V_{\mathrm{s}}} T^{4}-\sum_{i=1}^{m} n_{i} \Delta H_{T, t}^{0} \frac{\mathrm{d} F_{i}}{\mathrm{~d} t}\right)
$$

$2 \pi \varepsilon_{0} \varepsilon f_{\mathrm{m}} E^{2}$ : microwave power density reflecting the microwave absorbing characteristic of materials. $\frac{e a A}{V_{\mathrm{S}}} T^{4}$ : the heat dissipation of materials. $\sum_{i=1}^{m} n_{i} \Delta H_{T, t}^{0} \frac{\mathrm{d} F_{i}}{\mathrm{~d} t}$ : thermal effect of reactions.

Studies on the utilization of microwaves in vanadium extraction from stone coal have been under investigation for some years. In this extraction process, microwaves are usually 
used in the roasting and leaching stages to improve the recovery of vanadium. Most reports on this process focused on the effect of process parameters, such as microwave input power, temperature and heating time, on vanadium recovery. ${ }^{\mathbf{1 3 - 1 5}}$ Yuan et al. divided stone coal into different size grades and roasted it with microwaves. They found that the particle size of stone coal has a significant effect on the microwave roasting efficiency; however, the reason for this was not indicated. ${ }^{7}$

As mentioned above, the heating characteristics of natural ores in microwaves are related to their components. In stone coal, minerals with carbon are microwave absorbing minerals, and aluminosilicate minerals such as quartz, mica and illite are microwave transmitting minerals in general conditions. The existence of carbon in stone coal plays an important role in the microwave roasting of stone coal. Herein, the influence of carbon in stone coal on vanadium extraction by microwave roasting-acid leaching from stone coal was investigated. The relations of carbon content, particle size, microwave input power and vanadium leaching efficiency are analyzed and corresponding suggestions for the microwave roasting of stone coal are proposed.

\section{Experiment}

\subsection{Materials}

The vanadium-bearing stone coal used in this study was obtained from Teng-da Mining and Metallurgy Co. Ltd., Hubei, PR China. Its main chemical composition was analyzed via inductively coupled plasma-atomic emission spectroscopy (ICPAES), which is listed in Table 1. Its vanadium distribution was analyzed by electron probe microanalysis (EPMA) and valence state was analyzed by potentiometric titration, and the results are shown in Table 2. The XRD analysis, microscope image and main mineral composition of the raw ore are shown in Fig. 1, 2 and Table 3, respectively.

Tables 1 and 2 show that the raw ore is a typical low-grade mica type vanadium-bearing stone coal. The $\mathrm{V}_{2} \mathrm{O}_{5}$ grade is $0.72 \%$ and more than $90 \%$ of the vanadium exists in muscovite as V(III) and V(IV) without V(v). The occurrence state of vanadium in this stone coal indicates that the roasting process is

Table 1 Main chemical composition of the raw ore (wt\%)

\begin{tabular}{lllllllll}
\hline $\mathrm{V}_{2} \mathrm{O}_{5}$ & $\mathrm{SiO}_{2}$ & $\mathrm{Al}_{2} \mathrm{O}_{3}$ & $\mathrm{CaO}$ & $\mathrm{K}_{2} \mathrm{O}$ & $\mathrm{Na}_{2} \mathrm{O}$ & $\mathrm{Fe}_{2} \mathrm{O}_{3}$ & $\mathrm{~S}$ & $\mathrm{C}$ \\
\hline 0.72 & 65.19 & 9.92 & 5.28 & 2.64 & 0.14 & 5.16 & 3.11 & 13.32
\end{tabular}

Table 2 Vanadium distribution and valence state of raw ore (wt\%)

\begin{tabular}{|c|c|c|c|c|c|}
\hline & \multicolumn{2}{|c|}{ Vanadium distribution } & \multicolumn{3}{|c|}{$\begin{array}{l}\text { Vanadium valence } \\
\text { state }\end{array}$} \\
\hline & Muscovite & Organic matter & $\mathrm{V}(\mathrm{III})$ & $\mathrm{V}(\mathrm{Iv})$ & $\mathrm{V}(\mathrm{v})$ \\
\hline Relative content & 90.03 & 9.97 & 62.97 & 37.03 & 0 \\
\hline Content & 0.36 & 0.04 & 0.26 & 0.14 & 0 \\
\hline
\end{tabular}

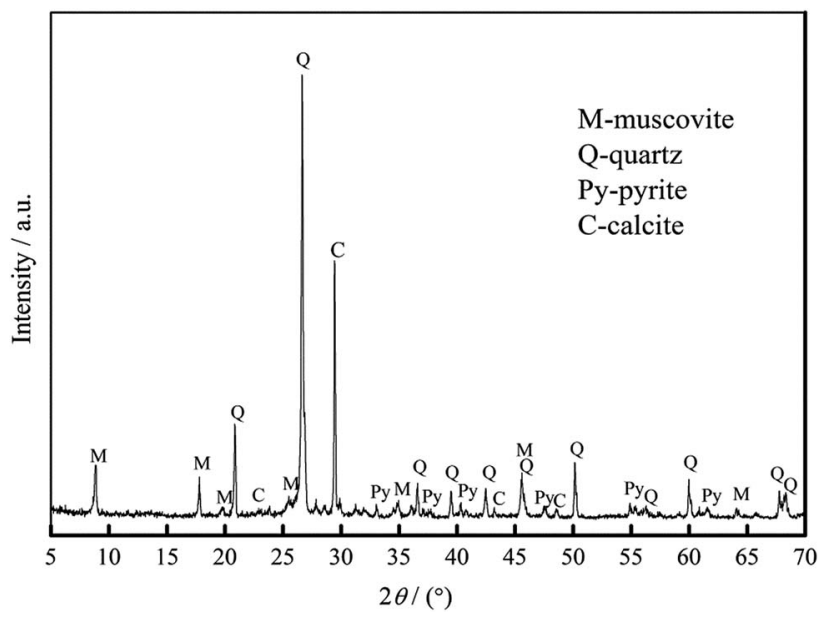

Fig. 1 XRD pattern of the raw ore.

necessary before acid leaching to destroy the muscovite structure and oxidize the low vanadium valence state.

As shown in Table 3, the raw ore mainly consists of $37 \%$ quartz, $13 \%$ coal, $11 \%$ calcite, $15 \%$ muscovite, $10 \%$ feldspar, $7 \%$ pyrite, $5 \%$ kaolinite and $2 \%$ other minerals.

\subsection{Methods}

The raw ore was crushed using a Jaw crusher $($ XPC-60 $\times 100)$ and double-roll crusher (HLXPS- $\varphi 250 \times 150)$ to $0-6 \mathrm{~mm}$. Then, the sample was divided into three different grade sizes, $0-1,1-3$ and 3-6 $\mathrm{mm}$.

Roasting experiments for stone coal and pure minerals were performed in the high-temperature microwave furnace (HMX08-16), as shown in Fig. 3, which was produced by the Kunming University of Science and Technology. The microwave input power was 0-6 kW and frequency was $2450 \pm 50 \mathrm{MHz}$. The temperature measurement system consists of infrared temperature measurement $\left(-50-2000{ }^{\circ} \mathrm{C}\right)$ and $\mathrm{K}$ type thermocouple measurement $\left(0-1100{ }^{\circ} \mathrm{C}\right)$.

The temperatures of the different sample layers were measured using a portable infrared thermometer $\left(-50-1200{ }^{\circ} \mathrm{C}\right)$.

All of the roasted samples were dry grinded to $-0.074 \mathrm{~mm}$, which accounted for more than $75 \%$, by a vibration mill (HLXZM-100). $50 \mathrm{~g}$ grinded sample was put into a $1000 \mathrm{~mL}$ beaker and the leaching experiment was carried out in magnetic and controlling temperature stirrers (SZCL-2A). The leaching experiment was conducted under conditions where the $\mathrm{H}_{2} \mathrm{SO}_{4}$ concentration, liquid/solid ratio, leaching temperature, and leaching time were set as 15\% (vol\%), $1.5: 1\left(\mathrm{~mL} \mathrm{~g}^{-1}\right), 95^{\circ} \mathrm{C}$ and $6 \mathrm{~h}$, respectively. The vanadium concentration of the leaching solution was measured using the ammonium ferrous sulfate method and the final vanadium leaching efficiency was the average value of three parallel experiments. ${ }^{16,17}$

\section{Results and discussion}

\subsection{Influence of carbon on microwave roasting of stone coal}

3.1.1 Influence on heating characteristic of stone coal. To investigate the heating behavior of each type of mineral listed in 

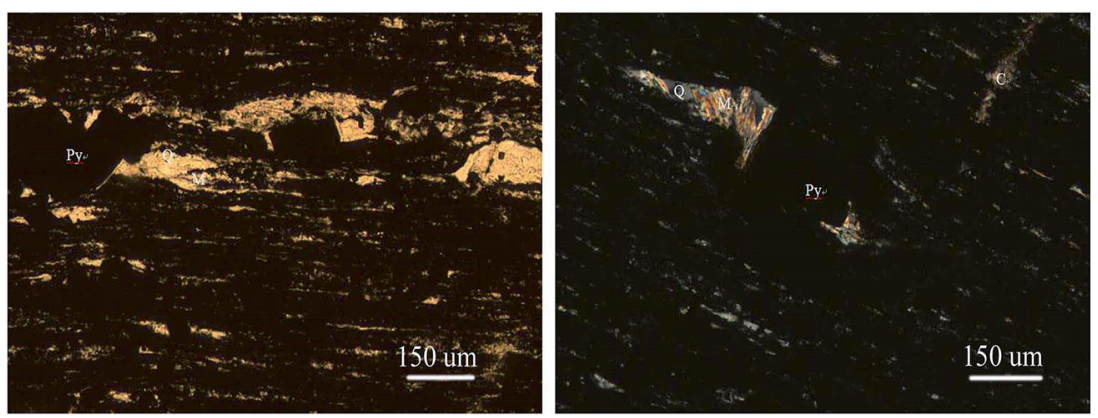

Fig. 2 Microscope image of the raw ore.

Table 3 Main mineral composition of the raw ore (wt\%)

\begin{tabular}{llllllll}
\hline Quartz & Coal & Calcite & Muscovite & Feldspar & Pyrite & Kaolinite & Other \\
\hline 37 & 13 & 11 & 15 & 10 & 7 & 5 & 2
\end{tabular}

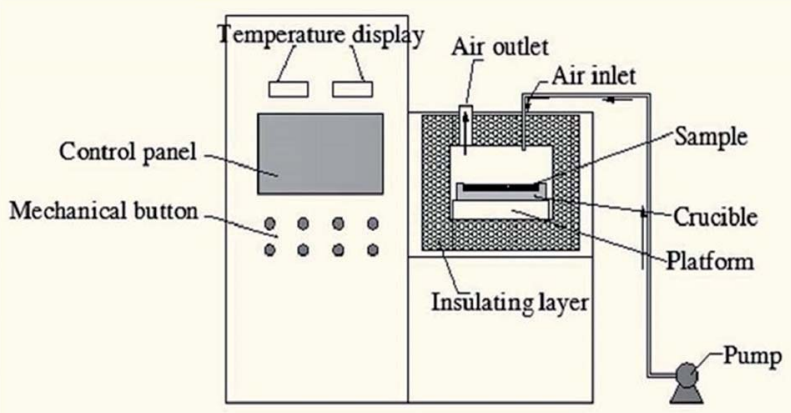

Fig. 3 Schematic of the microwave roasting equipment used in the experiment.

Table 3, $100 \mathrm{~g}$ of each pure mineral was roasted in the microwave furnace at $1500 \mathrm{~W}$ microwave input power, and the heating behavior of each type of mineral is shown in Fig. 4. The dotted

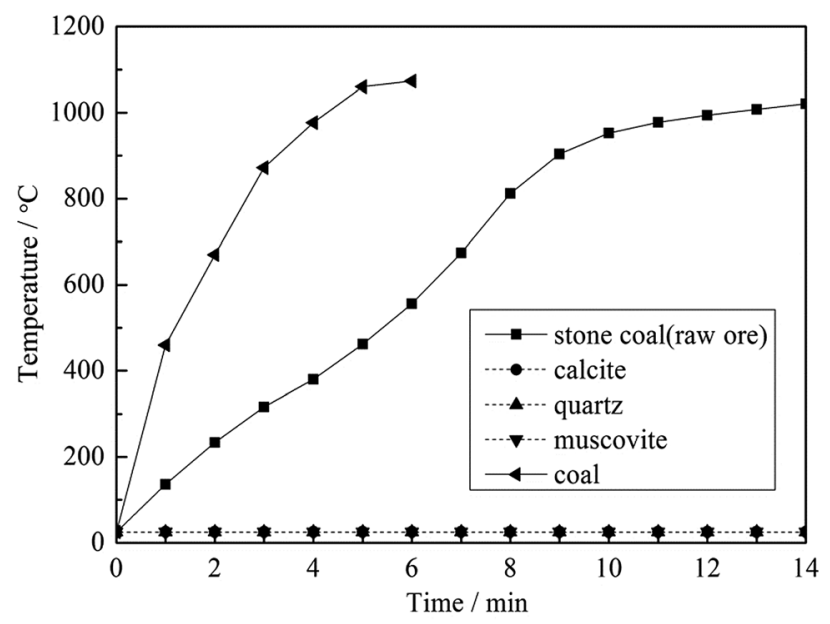

Fig. 4 Heating characteristics of the pure minerals. lines are the minerals that did not heat up under the experimental conditions. As shown in Fig. 4, coal is the main microwave absorbing mineral. The raw ore can absorb microwaves and heat up due to the existence of coal.

To clarify the influence of carbon content on the heating behavior of the material, pure muscovite with different coal contents was roasted in the microwave furnace at $1500 \mathrm{~W}$ microwave input power, and the results are shown in Fig. 5. As seen from Fig. 5, on one hand, with an increase in the carbon content in the material, the heating rate of the material in the microwave field increased. According to the Maxwell-Garnett equivalent medium theory of heterogeneous materials, the equivalent permittivity of a material increases with an increase in the content of high permittivity materials. ${ }^{12}$ This means that materials with a high carbon content have a high $\varepsilon$, and thus heat up quickly in a microwave field. On the other hand, the highest temperature that the materials could reach also increases along with an increase in carbon content. High temperature is an important factor in the roasting of stone coal; it has a significant effect on vanadium valency transformation and mineral structure destruction. Therefore, in terms of heating characteristics, carbon in stone coal is helpful for the microwave roasting process of stone coal; it provides stone coal with a high heating rate and high roasting temperature.

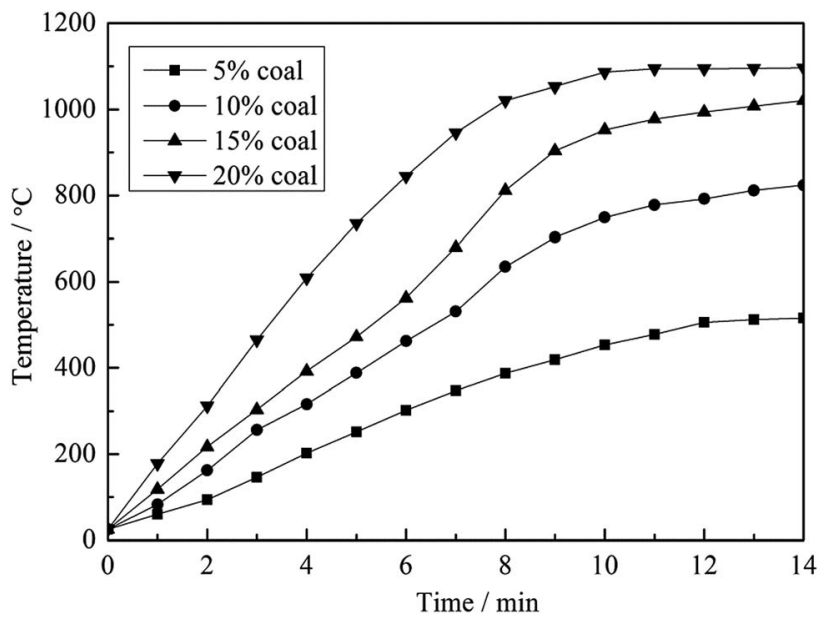

Fig. 5 Heating characteristic of pure muscovite with different carbon contents. 
3.1.2 Influence on vanadium valency. As shown in Table 2, most of the vanadium in the raw ore exists in the mica structure in a trivalent state, which is insoluble (or hardly soluble) in acid solution. One important purpose of roasting is to oxidize vanadium to higher valencies $\left(\mathrm{V}^{4+}\right.$ or $\left.\mathrm{V}^{5+}\right)$, which are soluble in acid. Carbon is a type of reducing material and it also reacts with oxygen in the roasting process and affects the oxidation of vanadium.

To investigate the effect of carbon on the vanadium valency, the thermodynamic calculation software, HSC Chemistry 6, was used to calculate the $\Delta G^{\theta}$ of the oxidation reactions of carbon and vanadium. The $\Delta G^{\theta}-T$ equation of each reaction (Table 4) was obtained by the least square method, and the Ellingham map is shown in Fig. 6. Based on the thermodynamic analysis, an experiment was performed for further proof. In this experiment, $100 \mathrm{~g}$ stone coal $(0-3 \mathrm{~mm})$ was roasted by $1000 \mathrm{~W}$ microwaves at $200{ }^{\circ} \mathrm{C}, 300{ }^{\circ} \mathrm{C}, 400{ }^{\circ} \mathrm{C}, 500{ }^{\circ} \mathrm{C}, 600{ }^{\circ} \mathrm{C}, 700{ }^{\circ} \mathrm{C}$ and $800{ }^{\circ} \mathrm{C}$ for $20 \mathrm{~min}$, respectively. The content of carbon and trivalent vanadium in the roasted samples are presented in Fig. 7.

According to Fig. 6 , the $\Delta G^{\theta}$ of the oxidation reactions of carbon is always less than that for the oxidation reactions of vanadium. This means that the oxidation reactions of carbon

Table 4 The possible reactions of carbon and vanadium oxide during the roasting process

\begin{tabular}{lll}
\hline Reaction & $\Delta G^{\theta}-T$ equation & Number \\
\hline $\mathrm{C}+\mathrm{CO}_{2}=2 \mathrm{CO}$ & $\Delta G^{\theta}=170707-174.047 T, \mathrm{~J}$ & $(2)$ \\
$2 \mathrm{CO}+\mathrm{O}_{2}=2 \mathrm{CO}_{2}$ & $\Delta G^{\theta}=-564840+173.64 T, \mathrm{~J}$ & $(3)$ \\
$\mathrm{C}+\mathrm{O}_{2}=\mathrm{CO}_{2}$ & $\Delta G^{\theta}=-394133-0.84 T, \mathrm{~J}$ & $(4)$ \\
$2 \mathrm{C}+\mathrm{O}_{2}=2 \mathrm{CO}$ & $\Delta G^{\theta}=-223426-175.31 T, \mathrm{~J}$ & $(5)$ \\
$2 \mathrm{~V}+\mathrm{O}_{2}=2 \mathrm{VO}$ & $\Delta G^{\theta}=-861904+185.02 T, \mathrm{~J}$ & $(6)$ \\
$4 / 3 \mathrm{~V}+\mathrm{O}_{2}=2 / 3 \mathrm{~V}_{2} \mathrm{O}_{3}$ & $\Delta G^{\theta}=-817274+178.01 T, \mathrm{~J}$ & $(7)$ \\
$4 / 5 \mathrm{~V}+\mathrm{O}_{2}=2 / 5 \mathrm{~V}_{2} \mathrm{O}_{5}$ & $\Delta G^{\theta}=-623081+175.76 T, \mathrm{~J}$ & $(8)$ \\
$4 \mathrm{VO}+\mathrm{O}_{2}=2 \mathrm{~V}_{2} \mathrm{O}_{3}$ & $\Delta G^{\theta}=-728016+164.07 T, \mathrm{~J}$ & $(9)$ \\
$2 \mathrm{~V}_{2} \mathrm{O}_{3}+\mathrm{O}_{2}=4 \mathrm{VO}_{2}$ & $\Delta G^{\theta}=-418400+195.81 T, \mathrm{~J}$ & $(10)$ \\
$4 \mathrm{VO}_{2}+\mathrm{O}_{2}=2 \mathrm{~V}_{2} \mathrm{O}_{5}$ & $\Delta G^{\theta}=-245182+148.95 T, \mathrm{~J}$ & $(11)$
\end{tabular}

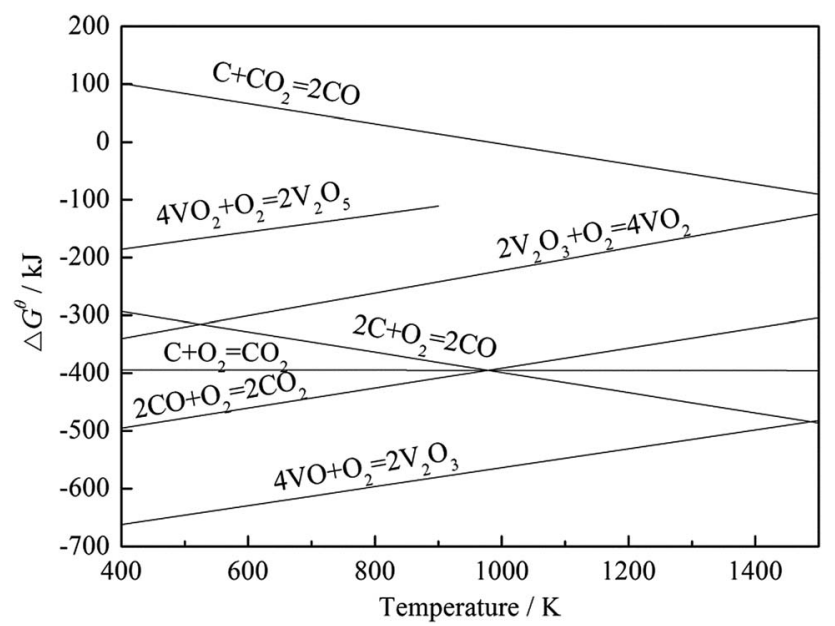

Fig. 6 Gibbs free energy diagram of the main reactions during the roasting process.

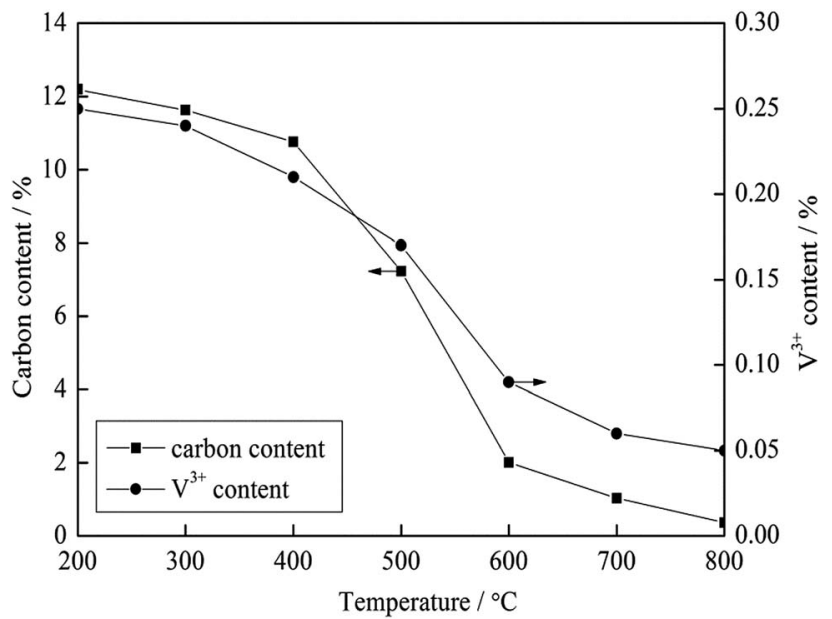

Fig. 7 Carbon and trivalent vanadium content of the roasted samples at different temperatures.

occur before vanadium, and thus more oxygen and energy are consumed by carbon before vanadium is oxidized. The result of the experiment, shown in Fig. 7, indicates that the content of $\mathrm{V}^{3+}$ decreases with a decrease in carbon content. Both the thermodynamic analysis and experiment research prove that carbon has an inhibitory effect on the oxidation of vanadium. Therefore, efficient decarburization in the roasting process could provide good oxidative reaction conditions for vanadium.

3.1.3 Influence on sintering phenomenon. In the conventional blank roasting process of $0-3 \mathrm{~mm}$ (the grain size in the conventional roasting process) stone coal, the sintering phenomenon (Fig. 8), which has serious inhibition on the vanadium leaching efficiency, occurs beyond $950{ }^{\circ} \mathrm{C} .{ }^{18}$ However, during the microwave roasting process, the sintering phenomenon happens at $750-850{ }^{\circ} \mathrm{C}$. The sintered samples generally appear in the internal position of the material pile. This part of the sample has a higher carbon content and temperature than the external sample without the sintering phenomenon (Fig. 9). This indicates that the carbon in this part of the sample can be hardly removed by reaction because of its poor permeability. It simultaneously resulted that the internal sample absorbed more microwaves and obtained a higher temperature than the external sample. In this sense, the carbon residue in stone coal is a main factor for the sintering phenomenon.

Generally, carbon in stone coal has double-edged roles for microwave roasting. On one hand, carbon provides stone coal with strong microwave absorbing characteristics to obtain a high heating rate and roasting temperature. On the other hand, carbon in stone coal inhibits the oxidization of vanadium and causes the sintering phenomenon.

\subsection{Microwave roasting of stone coal with size grading}

According to the abovementioned analysis, carbon in stone coal plays a double-edged role in the microwave roasting process of stone coal. In order to use the advantages and avoid the disadvantages of carbon in stone coal, the microwave roasting of stone coal with size grading was conducted. The raw ore was 

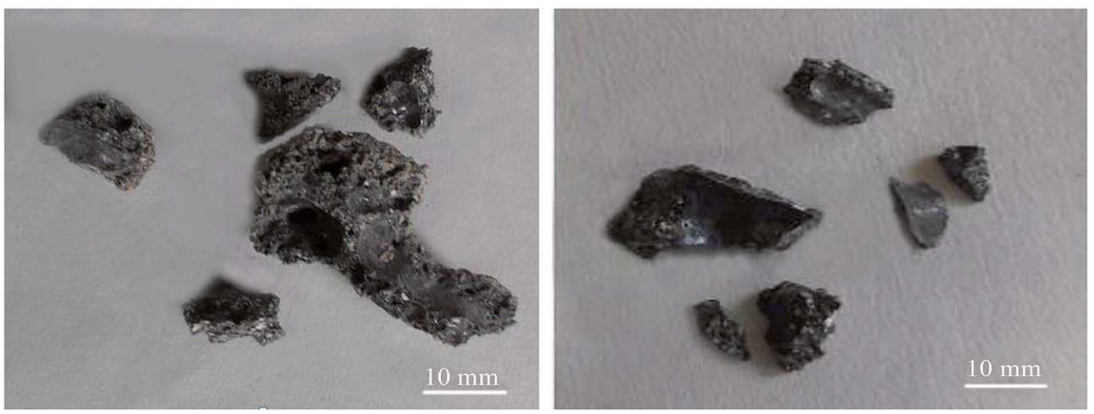

Fig. 8 Sintering phenomenon of stone coal during the microwave roasting process.

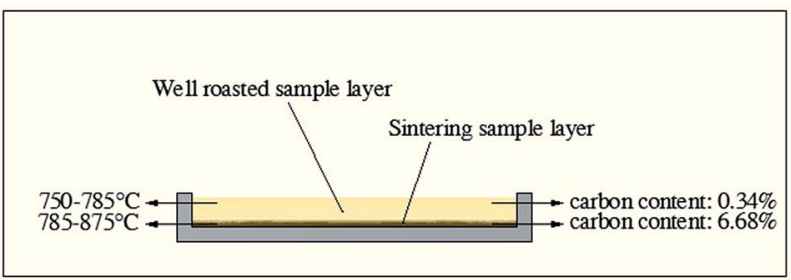

Fig. 9 Actual temperature and carbon content of different sample layers at $750{ }^{\circ} \mathrm{C}$ in microwave roasting.

Table 5 Analysis of the $\mathrm{V}_{2} \mathrm{O}_{5}$ grade and carbon content in different grain sizes (wt\%)

\begin{tabular}{llll}
\hline Grain size & $0-1 \mathrm{~mm}$ & $1-3 \mathrm{~mm}$ & $3-6 \mathrm{~mm}$ \\
$\mathrm{~V}_{2} \mathrm{O}_{5}$ grade & 0.77 & 0.63 & 0.58 \\
Carbon content & 13.69 & 12.67 & 12.48 \\
\hline
\end{tabular}

divided into three grain sizes, and the $\mathrm{V}_{2} \mathrm{O}_{5}$ grades and carbon contents are shown in Table 5. The heating characteristics and carbon content of each grain size at different input powers were investigated and acid leaching of the roasted samples was performed.

3.2.1 Heating characteristics and carbon content of samples. $200 \mathrm{~g}$ stone coal of each grain size was roasted in the microwave furnace at $600 \mathrm{~W}, 1200 \mathrm{~W}, 1800 \mathrm{~W}$ and $2400 \mathrm{~W}$, and the heating characteristics are shown in Fig. 10. The relationships of heating rates and highest temperatures that the sample can reach with particle sizes and microwave input powers are shown in a 3D graph (Fig. 11). The carbon contents of each size roasted sample at $600{ }^{\circ} \mathrm{C}$ for $0 \mathrm{~min}$ (representative of the heating stage) with different input powers are shown in Fig. 12(a).

As shown in Fig. 10 and 11, the heating characteristics of the different grain sizes with different input powers are quite different. At the same input power, the heating rate and the highest roasting temperature increase with an increase in particle size. According to eqn (1), there are two reasons for this phenomenon. First, fine grained stone coal has higher heat dissipation than coarse particles due to its higher specific surface area, which decreases the heating rate of fine particles. Second, according to Fig. 12(a), the carbon contents of coarse particles are always higher than the fine particles in the heating stage because of the poor gas transfer conditions in the particles. This means that the coarse particles have higher equivalent permittivity, which causes a better microwave absorbing property. In this respect, in order to obtain a high heating rate and roasting temperature in the microwave roasting process, the size of stone coal should not be too fine.

Furthermore, for each grain size, the heating rate and highest temperature increase with an increase in input power. On one hand, a high microwave input power causes a high microwave power density. This means that more microwave energy is absorbed and transformed into heat by stone coal, consequently increasing the heating rate. On the other hand, the time to reach a certain temperature decreases with an increase in input power. This means that the reaction time of carbon with oxygen is shorter and less carbon is removed in the heating stage. There would be more carbon left to absorb microwaves and heat. In this sense, a high input power will be benefited by heating rate and highest temperature.

Generally, the carbon content of the samples in the heating stage has a significant effect on their heating characteristics, and they had similar changing tendencies when the grain size and microwave input power changed. A higher microwave input power and larger particle size ensure that more carbon is left in the samples in the heating stage and that the samples would obtain higher heating rates and roasting temperatures.

However, as mentioned above, high carbon content has synchronous disadvantages for microwave roasting. If the carbon residue in stone coal can be removed as much as possible in the high temperature holding stage, these disadvantages would be avoided. To investigate the final decarburization of each grain size at different input powers during the entire roasting stage, all the grain sizes were roasted at $800{ }^{\circ} \mathrm{C}$ for $30 \mathrm{~min}$ at different input powers, and the result is shown in Fig. 12(b).

According to Fig. 12(b), for $0-1 \mathrm{~mm}$ stone coal, the final carbon content increased with an increase in the input power because of the severe sintering phenomenon. More carbon was wrapped up by material with a low melting point because of the sintering phenomenon. Regarding 1-3 $\mathrm{mm}$ and 3-6 $\mathrm{mm}$, the final carbon content decreased when the input power changed from $600 \mathrm{~W}$ to $1800 \mathrm{~W}$ and then increased beyond $1800 \mathrm{~W}$. As shown in Fig. 13, the roasted sample of coarse particles at $1800 \mathrm{~W}$ has several evident cracks and gaps; however, the 

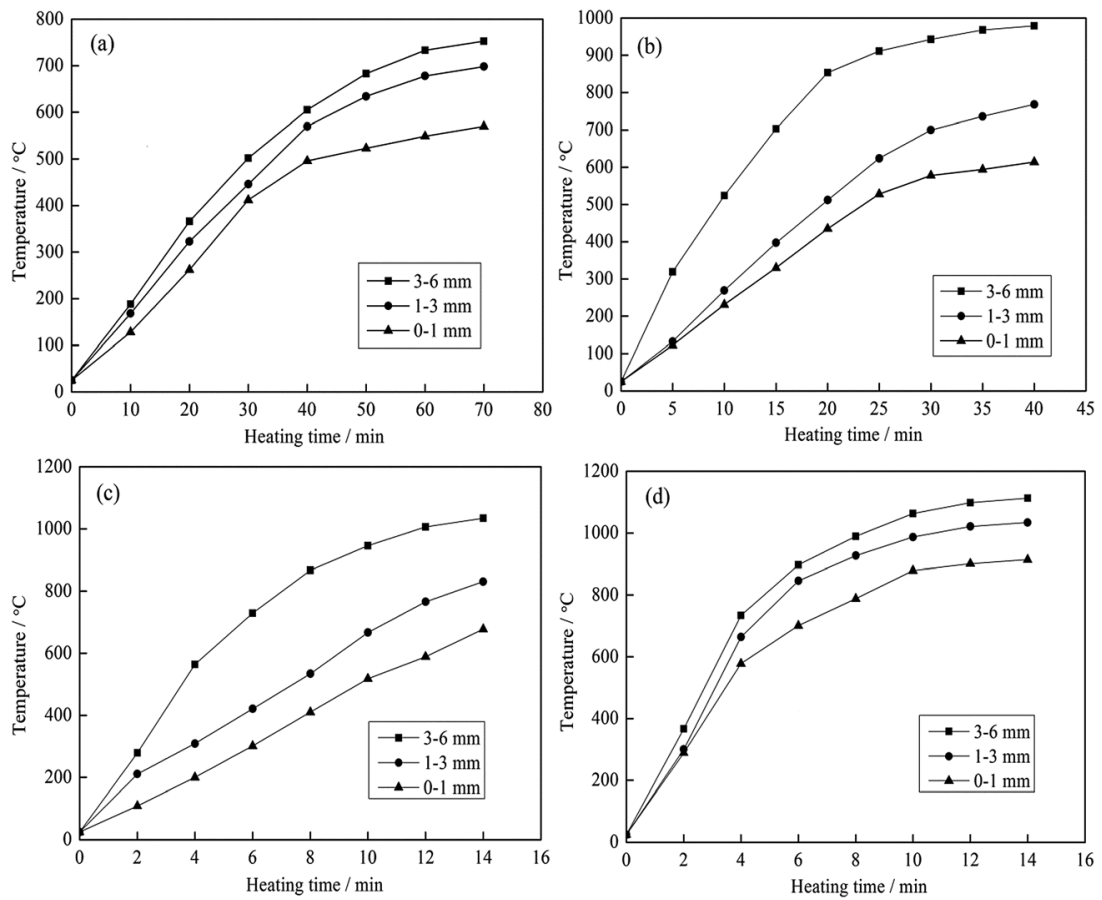

Fig. 10 Heating characteristics of the different grain sizes at different microwave input powers ((a) 600 W; (b) 1200 W; (c) 1800 W and (d) 2400 W).
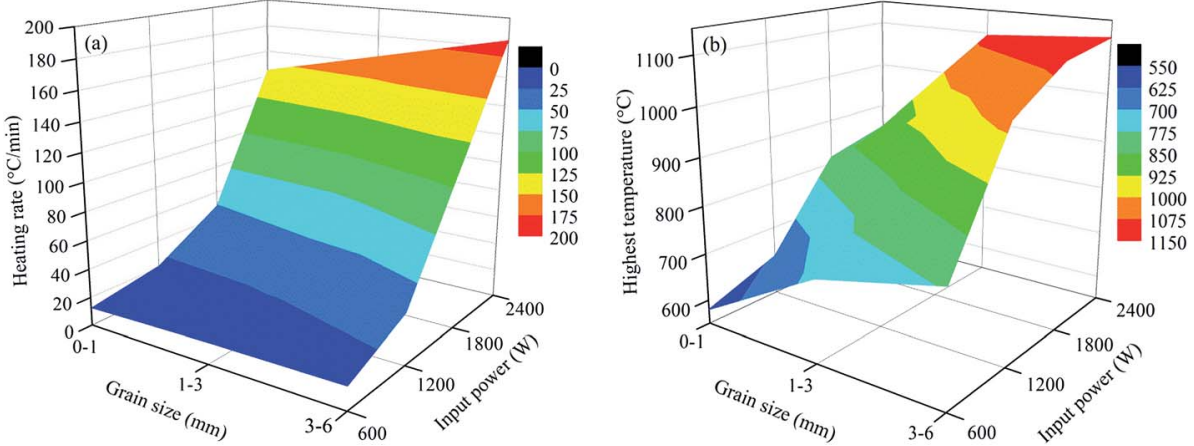

Fig. 11 Relationship between the heating rate and highest temperature with grain sizes and input powers ((a) heating rate and (b) highest temperature).
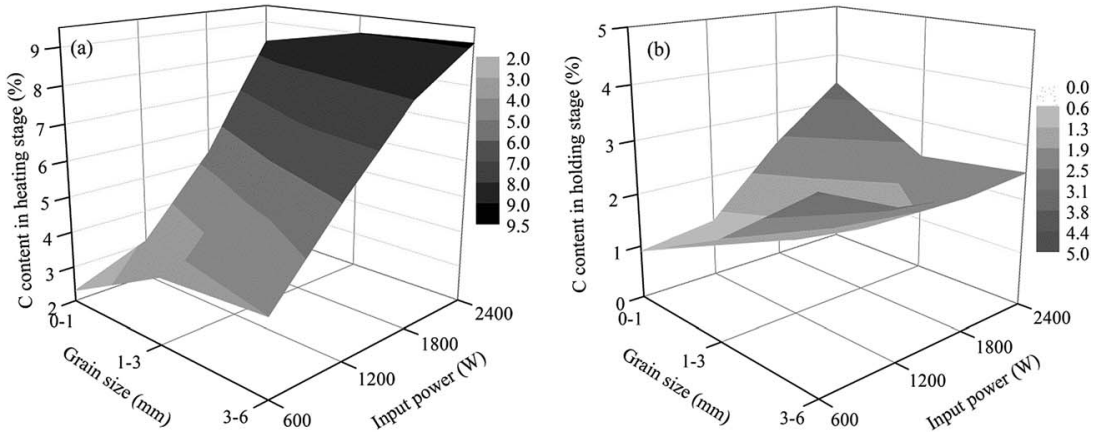

Fig. 12 Carbon contents of the samples in different stages of the roasting process ((a) carbon content in the heating stage and (b) carbon content in the high temperature holding stage). 


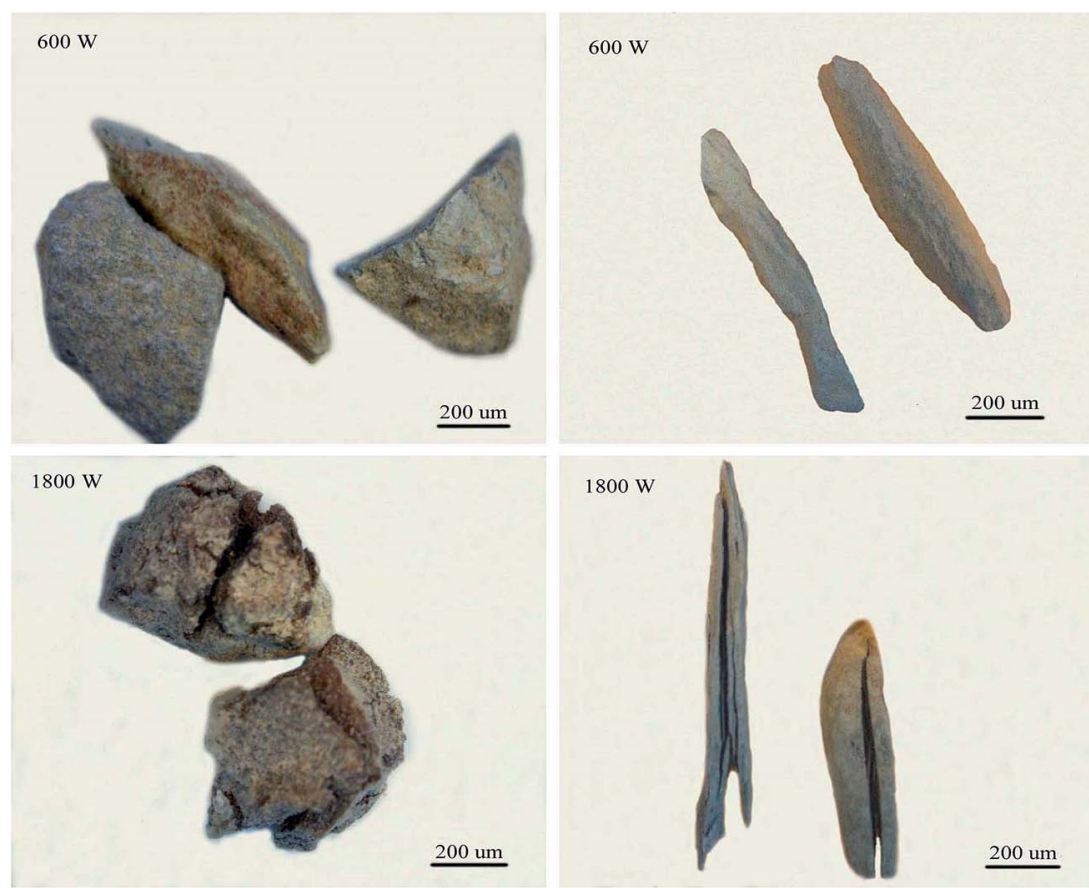

Fig. 13 Roasted sample of coarse grained stone coal at $800{ }^{\circ} \mathrm{C}$ for $30 \mathrm{~min}$ at 600 and $1800 \mathrm{~W}$.

roasted sample at low input power has no cracks and gaps. These cracks and gaps are mainly because of the selective heating characteristic of microwave heating. ${ }^{19}$ They provide better transfer conditions for the reaction of carbon with oxygen in the high temperature holding stage. However, too large particle size (3-6 $\mathrm{mm}$ in this experiment) would decrease the decarburization efficiency and there also exists the sintering phenomenon of coarse particles when the input power is too high, which leads to an increase in the final carbon content.

Generally speaking, enough cracks and gaps in the particles could ensure relatively complete decarburization in the high temperature holding stage. The synergistic action gained from
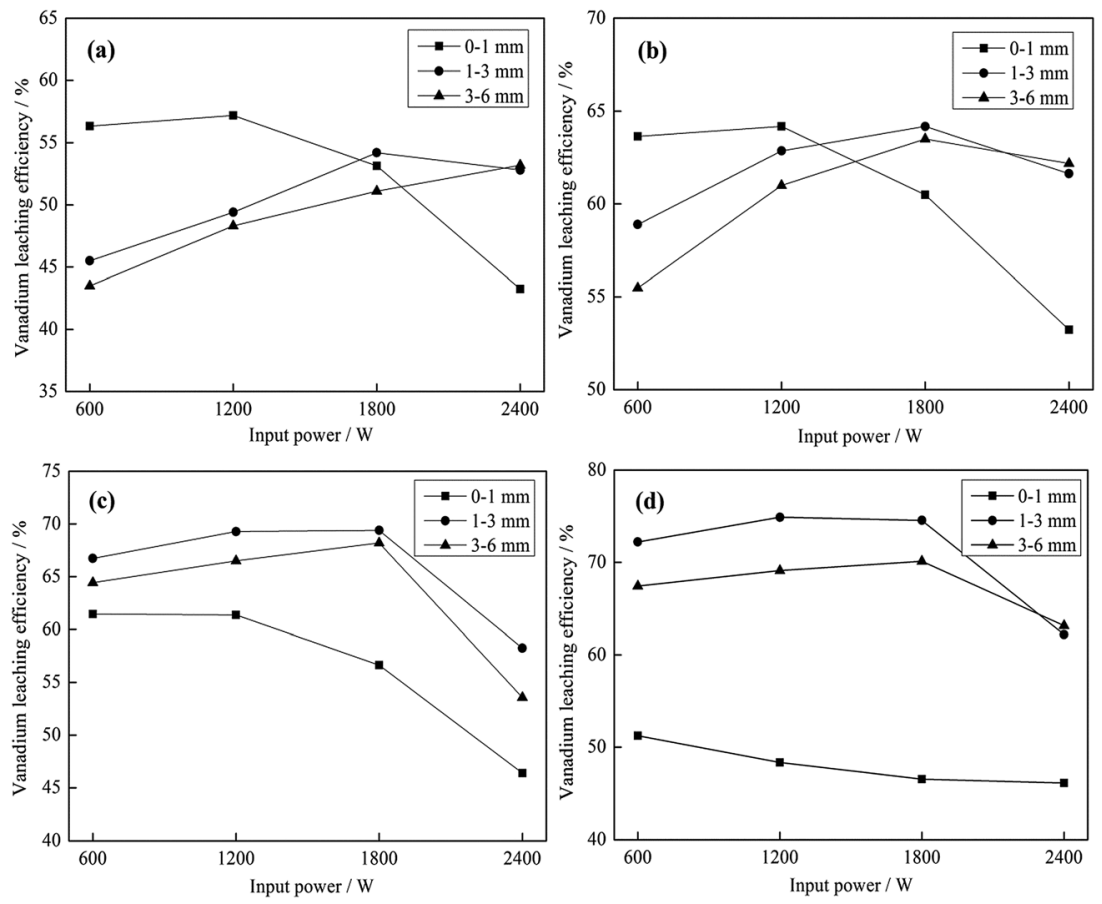

Fig. 14 Vanadium leaching efficiencies of the roasted samples in different microwave roasting conditions $\left((\mathrm{a})\right.$ roasted at $700{ }^{\circ} \mathrm{C} ;(\mathrm{b})$ roasted at $750{ }^{\circ} \mathrm{C}$; (c) roasted at $800^{\circ} \mathrm{C}$; and (d) roasted at $850{ }^{\circ} \mathrm{C}$ ). 
a suitable particle size (1-3 $\mathrm{mm})$ and microwave input power (1200-1800 W) provides the samples with a large number of cracks and gaps, which ensure the final decarburization efficiency.

3.2.2 Leaching efficiencies of the roasted samples. The grain size and input power are adjusted to obtain a high heating rate, high roasting temperature with high final decarburization efficiency and avoid the sintering phenomenon. The main purpose of roasting is to obtain a high vanadium leaching efficiency. In order to investigate whether this adjustment can improve the vanadium leaching of roasted samples, leaching experiments for the corresponding roasted samples were conducted. Each size of stone coal was roasted at $700{ }^{\circ} \mathrm{C}, 750{ }^{\circ} \mathrm{C}$, $800{ }^{\circ} \mathrm{C}$ and $850{ }^{\circ} \mathrm{C}$ for $30 \mathrm{~min}$ at $600 \mathrm{~W}, 1200 \mathrm{~W}, 1800 \mathrm{~W}$ and

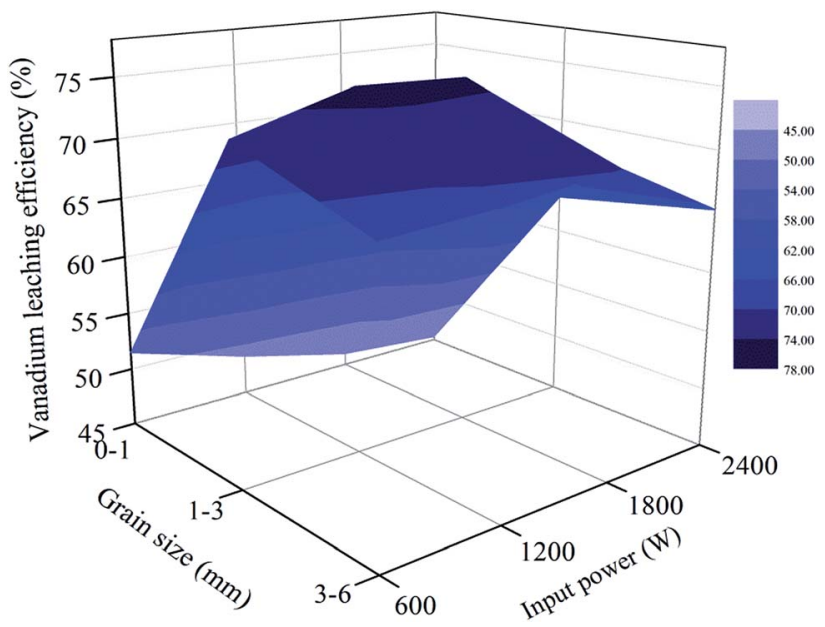

Fig. 15 Relationship between vanadium leaching efficiency and grain size and microwave input power $\left(850^{\circ} \mathrm{C}\right.$ for $\left.30 \mathrm{~min}\right)$.
$2400 \mathrm{~W}$. These results are shown in Fig. 14 and the result of $850{ }^{\circ} \mathrm{C}$ is also shown as a $3 \mathrm{D}$ graph in Fig. 15 to analyze the relationship between vanadium leaching efficiency and grain size and microwave input power.

As seen from Fig. 14, there is a downward trend of vanadium leaching efficiency for $0-1 \mathrm{~mm}$ when the roasting temperature is higher than $750{ }^{\circ} \mathrm{C}$. At each temperature, the vanadium leaching efficiency of this part of stone coal decreased with an increase in input power. When the temperature was higher than $750{ }^{\circ} \mathrm{C}$, the sintering phenomenon of these particles was prominent and a higher input power caused more severe sintering. However, this temperature level was not high enough to destroy the vanadium-bearing mineral completely and the vanadium leaching efficiencies were less than $60 \%$. With respect to the coarse particles, the overall trend of vanadium leaching efficiency is upward with an increase in the roasting temperature, which increased before $1800 \mathrm{~W}$ and decreased above it. In the process of the experiment, there was almost no sintering phenomenon of coarse particles. This provided better conditions for stone coal to reach a higher temperature to destroy the structure of the vanadium-bearing mica. Furthermore, the cracks and gaps of coarse particles at high input power are also helpful for the transformation of the acid solution in particles.

From Fig. 12(b) and 15, it is not difficult to see that there is a clear correlation between vanadium leaching efficiency and final carbon content of the roasted sample. The vanadium leaching efficiencies of the 1-3 mm roasted samples with 1200$1800 \mathrm{~W}$ are higher than the samples roasted in other conditions. This indicates that the adjustment of grain size and microwave input power for heating characteristic could also improve the vanadium leaching efficiency. In the acid leaching condition of this experiment, the vanadium leaching efficiency

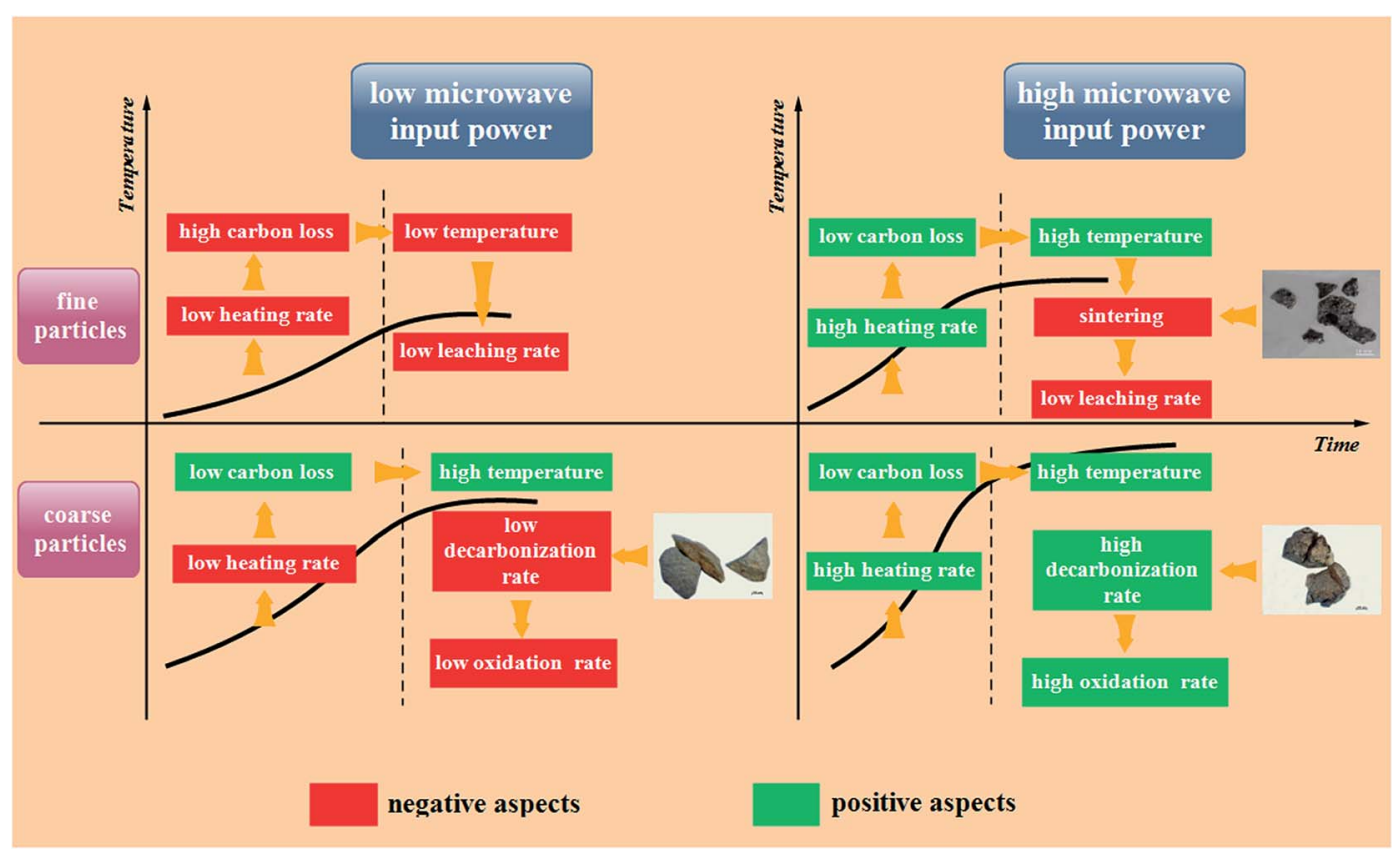

Fig. 16 Schematic of the general rules during the microwave roasting of fine and coarse particles. 
of the roasted sample with $1200-1800 \mathrm{~W}$ input power at $850{ }^{\circ} \mathrm{C}$ for $30 \mathrm{~min}$ reached $76.3 \%$, which is $14 \%$ higher than that of the roasted samples without size grading under the same roasting conditions. $^{7}$

Based on the analyses mentioned above, the general rules during the microwave roasting of fine and coarse particles can be described as shown in Fig. 16.

As for the fine particles, low microwave input power causes them to heat up slowly in the heating stage and this extends the heating time, which results in high carbon loss in this stage. The microwave absorption capacity of fine particles decreases with an increase in carbon loss. Hence, the final temperature of these particles cannot reach the appropriate level to destroy the structures of vanadium-bearing minerals, which results in a low vanadium leaching efficiency. A high microwave input power causes the fine particles to have a high heating rate and a low carbon loss in the heating stage, which results in a high final temperature. However, the sintering phenomenon is incidental for the fine particles at a high temperature, which decreases the vanadium leaching rate significantly.

For the coarse particles, although a low microwave input power also causes them to heat up slowly and extend the heating time, the loss of carbon is not high in the heating stage due to the large particle size. Hence, they have a good microwave absorption capacity to obtain a high final temperature. However, the large particle size also hinders the vanadium oxidation rate, which has a negative effect on the vanadium leaching rate. A high microwave input power not only provides coarse particles with a high heating rate and a high final temperature, but also a high oxidation rate because of the abundant cracks and pores, which increase the vanadium leaching rate.

\section{Conclusion}

(1) Carbon is an important microwave absorbing material in this type of stone coal and it provides stone coal with good heating characteristics. However, the negative effects of carbon include the inhibition of the oxidization of vanadium and causing the sintering phenomenon.

(2) For fine stone coal, because of its high decarbonization rate in the heating stage and high heat dissipation due to its high specific surface area, the heating rate and highest temperature for this part of stone coal are always low. Moreover, the vanadium leaching efficiency of these particles is not high because of their obvious sintering phenomenon.

(3) In contrast to fine stone coal, coarse particles have a higher heating rate and higher temperature during the microwave roasting process because of their low decarbonization rate and heat dissipation. A high input power in coarse particles roasting causes more carbon to be retained in stone coal in the heating stage and it is removed in the high temperature holding stage due to the cracks and gaps of the coarse particles. In this way, the advantages of carbon are used and its disadvantages are avoided. There is almost no sintering phenomenon in coarse particles. This provides better conditions for stone coal to reach a higher temperature to destroy the structure of vanadium-bearing mica.

(4) For this type of stone coal, a 1-3 mm size and 1200$1800 \mathrm{~W}$ input power are suitable, the vanadium leaching efficiency reaches $76.3 \%$ at $850{ }^{\circ} \mathrm{C}$ for $30 \mathrm{~min}$, and it is $14 \%$ higher than the roasted samples without size grading.

\section{Acknowledgements}

This study was supported by the Project of National Natural Science Foundation of China (No. 51474162 \& No. 51404174) and the National Key Technology Support Program of China (2015BAB18B01).

\section{References}

1 Y. M. Zhang, S. X. Bao, T. Liu, T. J. Chen and J. Huang, Hydrometallurgy, 2011, 109(1-2), 116.

2 H. L. Wu, C. Wei, G. Fan, M. Y. Li, Z. G. Deng and H. W. Ge, J. Kunming Univ. Sci. Technol., Nat. Sci. Ed., 2008, 33(6), 17.

3 M. Y. Wang and X. W. Wang, Chin. J. Rare Met., 2010, 34(1), 90.

4 X. B. Zhu, Y. M. Zhang and T. Liu, Chin. J. Rare Met., 2013, 37(2), 283.

5 Y. H. Liu, C. Yang, P. Y. Li and S. Q. Li, Int. J. Miner., Metall. Mater., 2010, 17(4), 381.

6 D. S. He, Q. M. Feng, G. F. Zhang, L. M. Ou and Y. P. Lu, Min. Eng., 2007, 20, 1184.

7 Y. Z. Yuan, Y. M. Zhang, T. J. Chen, T. Liu, F. Wang and J. Liu, Chin. J. Rare Met., 2014, 38(3), 534.

8 T. J. Chen, G. Z. Qiu and D. Q. Zhu, Min. Miner. Eng., 2008, 28(3), 64.

9 W. Q. Cai, H. Q. Li and Y. Zhang, Chin. J. Process Eng., 2005, 5(2), 228.

10 D. A. Jones, T. P. Lelyveld, S. D. Mavrofidis, S. W. Kingman and N. J. Miles, Resour., Conserv. Recycl., 2002, 34(2), 75.

11 C. A. Pickles, Min. Eng., 2004, 17, 775.

12 J. H. Peng, and B. G. Liu, Microwave Calcination Technology and Application, Science Press, Beijing, 2013, p. 71.

13 J. Yu, Z. Z. Zhu and J. Yang, Hydrometall. China, 2011, 30(2), 111.

14 H. Wang, X. Z. Lan, H. Z. Ma and Y. H. Song, Hydrometall. China, 2011, 30(4), 290.

15 X. Y. Zhang, W. Q. Qin, X. D. Tian, Y. B. Chen, Y. Gu and X. G. Xi, Chin. J. of Nonferrous Met., 2011, $21(4), 908$.

16 China Metallurgical Information and Standardization Institute, GB/T 8704.5-2007 Ferrovanadium-Determination of Vanadium Content-the Ammonium Ferrous Sulfate Titrimetric Method and the Potentiometric Titrimetric Method, 2007.

17 F. Wang, Y. M. Zhang, J. Huang, T. Liu, X. Yang, Y. Wang and J. Zhao, Rare Met., 2013, 32(1), 57.

18 M. Lu, Y. M. Zhang, T. Liu and D. Yang, Chin. J. Rare Met., 2009, 33(6), 894.

19 G. Q. Ou Yang, X. Y. Zhang, X. D. Tian, Y. Li and S. Xie, Chin. J. of Nonferrous Met., 2008, 18(4), 750. 